\title{
DIABETIC RETINOPATHY AND ITS' ASSOCIATION WITH CAROTID INTIMA MEDIA THICKNESS.
}

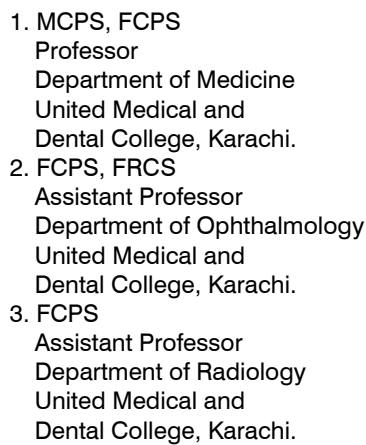

Correspondence Address:

Dr. Farhat Bashir

40-B, $1^{\text {st }}$ East Street,

Phase 1, DHA, Karachi.

drfarhatbashir@gmail.com

Article received on: 07/12/2018

Accepted for publication: 04/04/2019

Received after proof reading:

28/08/2019

\begin{abstract}
Farhat Bashir ${ }^{1}$, Beenish Khan ${ }^{2}$, Shehla Tanveer ${ }^{3}$
ABSTRACT... Objectives: To evaluate the association of diabetic retinopathy (DR) and CIMT (carotid intima-media thickness) in diabetic subjects and to identify the factors contributing to retinopathy. Study Design: Comparative cross-sectional study. Setting: Creek General Hospital, United Medical and Dental College. Period: August 2017 to July 2018. Material and Methods: After identification of 62 subjects with type 2 diabetes mellitus for the study, their complete history, physical examination and relevant laboratory investigations were recorded. The diabetic retinopathy was assessed by ophthalmoscopy. All subjects underwent Doppler ultrasound scanning of the carotid arteries for measurement of CIMT (carotid intima-media thickness). The data was analyzed through SPSS version 20.0. Student's t-test was used to assess the association between retinopathy and CIMT and other continuous variables. The association of categorical variables was assessed by Chi-square. P-value of $<0.05$ was considered significant. Results: The target population constituted $29 \%$ males and $71 \%$ females. Among the participating subjects $50.2 \%$ had retinopathy while $49.8 \%$ subjects without retinopathy were included in the study. There was a strong association of retinopathy with carotid intimamedia thickness. Retinopathy was also associated with duration of diabetes mellitus, measures of glycemic control, serum creatinine levels, total cholesterol, LDL cholesterol, and serum triglycerides. Conclusion: Retinopathy is strongly associated with CIMT. Poor glycemic control, nephropathy, dyslipidemia and duration of diabetes also show association with retinopathy.
\end{abstract}

Key words: Carotid Intima-Media Thickness (CIMT), Retinopathy, Type 2 Diabetes Mellitus.

Article Citation: Bashir F, Khan B, Tanveer S. Diabetic retinopathy and its' association with carotid intima media thickness. Professional Med J 2019; 26(9):1445-1450. DOI: 10.29309/TPMJ/2019.26.09.2040

\section{INTRODUCTION}

Prevalence of diabetes mellitus is increasing in developing countries as a result of changing lifestyle, diet and obesity. Diabetes and impaired glucose intolerance is affecting around $22 \%$ of the population in Pakistan. ${ }^{1}$ Disability and mortality associated with diabetes are linked to its complications. Diabetic retinopathy is the $2^{\text {nd }}$ leading cause of blindness in the world. ${ }^{2}$ Diabetic retinopathy is associated with type of diabetes mellitus, duration of diabetes and glycemic control, dyslipidemia, hypertension, smoking, pregnancy, and nephropathy. ${ }^{3}$ These factors are also associated with cardiovascular disease. Cardiovascular disease occurs as a sequel of atherosclerosis. Atherosclerosis is associated with age, obesity, smoking, duration of diabetes and glycemic control, dyslipidemia, hypertension and nephropathy in the diabetic person. Even diabetics with satisfactory glycemic control have twice the chance of cardiovascular mortality. ${ }^{4}$ Atherosclerosis is diabetes is due not only to the metabolic abnormalities associated with it but also occurs as a result of the pro-inflammatory effect of hyperglycemia.

The concurrence of microvascular and macrovascular complications of diabetes may be a result of similar metabolic disturbances and pathogenesis. ${ }^{5}$ Some of these mechanisms are glycemic and oxidative stress, chronic low grade inflammation and impaired vascular tissue repair. ${ }^{6}$

Hypoxia leads to angiogenesis in diabetic retinopathy. Hypoxia may also contribute to the cardiovascular disease by causing 
microangiopathy in these patients. ${ }^{7}$ ACCORD showed that the risk of developing cardiovascular disease increased in diabetic patients with severe retinopathy as compared to those with mild non-proliferative retinopathy. ${ }^{8}$ Severe diabetic retinopathy has shown association with increased CIMT and coronary artery calcification in type 1 diabetic patients with sub-clinical ischemic heart disease. ${ }^{9,10}$

Atherosclerosis can be measured non-invasively by carotid Doppler studies. This can be used to measure Carotid intima-media thickness (IMT) and assess for carotid plaques. ${ }^{11}$ Increase in CIMT and presence of carotid plaques are associated with CV risk factors. ${ }^{12,13}$ they are also used to predict CV events independently of risk factors, ${ }^{14}$ and can help to stratify patients into different risk categories ${ }^{15}$ thus adding more accuracy to the current risk analysis methods.

The purpose of this study was to evaluate the association of CIMT with retinopathy in patients with type 2 diabetes mellitus and to assess the cardio-metabolic risk factors associated with retinopathy.

\section{SUBJECTS AND METHODS}

This comparative cross sectional study was conducted at Creek General Hospital, United Medical and Dental College for the duration of one year starting from 1st August 2017 to 31st July 2018. The institutional review board provided approval for the study. A total of 62 patients were included in the study through non probability purposive sampling. An informed consent was taken after explaining the whole procedure. All adult subjects who fulfilled the diagnostic criteria of type 2 diabetes mellitus were included in the study. The exclusion criteria included only eyed patients in whom one eye was damaged because of any reason, ocular comorbidities other than diabetic retinopathy like age related macular degeneration, retinal dystrophy, glaucoma etc; and subjects in whom fundus visualization was not possible.

Subjects fulfilling the criteria were selected from the Out-patient department of Ophthalmology and Internal Medicine. A detailed proforma was used to gather data regarding the subjects' details and laboratory investigations. All the subjects underwent slit lamp examination of both eyes including +90D and +78D lens examination after dilatation with $1 \%$ tropicamide. Staging of the diabetic retinopathy was done clinically. Carotid intima media thickness was evaluated in both common carotid arteries of each patient by a single radiographer using a $7.5 \mathrm{MHz}$ linear transducer probe of a B-mode Doppler ultrasound (Toshiba Nemio 35). CIMT was calculated as the linear distance between the lumen-intima interface and media-adventitia interface.

Statistical Packages for Social Science (SPSS version 20.0) was used to analyze data. Mean with standard deviation was calculated for quantitative variables. Frequency and percentage was used for qualitative variables. The association of the quantitative variables with retinopathy was assessed by Student's t- test while that of qualitative variables was assessed through Chi square test, $\mathrm{p}$-value $<0.05$ was considered significant.

\section{RESULTS}

The study population included 26 patients with retinopathy and 36 patients without retinopathy. There were 18 male and 44 female subjects. The mean age of the patients was $51.2 \pm 9.8$ years. (Table-l) All the indicators of glycemic control, serum creatinine, total cholesterol, LDL cholesterol and triglycerides were also significantly high in patients with retinopathy. Both the left and right eye retinopathy was associated with the CIMT of the respective eye.

\section{DISCUSSION}

Diabetes mellitus can cause microvascular (retinopathy, neuropathy and nephropathy) and macrovascular (cardiovascular disease [CVD], peripheral arterial disease and cerebrovascular disease) complications. The co-existence of both micro and macrovascular complications points towards a common pathophysiological etiology contributing towards them. 


\begin{tabular}{|c|c|c|c|c|c|}
\hline \multicolumn{2}{|c|}{ Variables } & $\begin{array}{c}\text { Total } \\
\text { population }\end{array}$ & $\begin{array}{l}\text { Patients with } \\
\text { retinopathy (cases) } \\
\mathrm{N}=26(50.2 \%)\end{array}$ & $\begin{array}{l}\text { Patients without } \\
\text { retinopathy(controls) } \\
N=36(49.8 \%)\end{array}$ & p-value \\
\hline \multicolumn{2}{|l|}{ Age (years) } & $51.2 \pm 9.8$ & $53.4 \pm 8.7$ & $49.6 \pm 10.4$ & $0.13 \#$ \\
\hline \multirow{2}{*}{ Gender } & Male & $18(29 \%)$ & $6(\%)$ & $12(\%)$ & \multirow{2}{*}{$0.4^{*}$} \\
\hline & Female & $44(71 \%)$ & $20(\%)$ & $24(\%)$ & \\
\hline \multirow[t]{2}{*}{ Hypertension } & Yes & $35(56.55 \%)$ & $19(\%)$ & $16(\%)$ & \multirow{2}{*}{$0.6^{*}$} \\
\hline & No & $27(43.5 \%)$ & $17(\%)$ & $10(\%)$ & \\
\hline \multicolumn{2}{|c|}{ Duration of diabetes (years) } & $9.5 \pm 8.1$ & $12.0 \pm 8.5$ & $7.8 \pm 7.4$ & $0.04 \#$ \\
\hline \multicolumn{2}{|c|}{ Waist circumference (inches) } & $37.7 \pm 5.8$ & $37 \pm 5.1$ & $38.3 \pm 6.2$ & $0.35 \#$ \\
\hline \multicolumn{2}{|l|}{$\mathrm{BMI} \mathrm{kg/ \textrm {m } ^ { 2 }}$} & $26.6 \pm 5.2$ & $27.2 \pm 6.5$ & $26.1 \pm 4.04$ & $0.48 \#$ \\
\hline \multicolumn{2}{|c|}{ Systolic BP (mmHg) } & $112.7 \pm 14.39$ & $112.7 \pm 14.5$ & $112.7 \pm 14.6$ & $0.98 \#$ \\
\hline \multicolumn{2}{|c|}{ Diastolic BP (mmHg) } & $71.0 \pm 9.79$ & $73.4 \pm 10.6$ & $69.3 \pm 8.9$ & $0.1 \#$ \\
\hline \multicolumn{2}{|c|}{ Fasting blood glucose (mg/dl) } & $175.56 \pm 60.98$ & $164.2 \pm 49.7$ & $196.3 \pm 67.9$ & $0.04 \#$ \\
\hline \multicolumn{2}{|c|}{ Random blood glucose (mg/dl) } & $269.93 \pm 91.9$ & $250.7 \pm 96.4$ & $297.8 \pm 78$ & $0.03 \#$ \\
\hline \multicolumn{2}{|c|}{$\mathrm{HbA} 1 \mathrm{c} \%$} & $9.56 \pm 2.1$ & $9.01 \pm 1.9$ & $10.3 \pm 2.1$ & $0.01 \#$ \\
\hline \multicolumn{2}{|c|}{ Total cholesterol (mg/dl) } & $179.54 \pm 38.5$ & $203.3 \pm 28.9$ & $183.5 \pm 36.6$ & $0.02 \#$ \\
\hline \multicolumn{2}{|l|}{ LDL (mg/dl) } & $113.5 \pm 32.6$ & $137.7 \pm 21.7$ & $115.1 \pm 29.1$ & $0.001 \#$ \\
\hline \multicolumn{2}{|l|}{$\mathrm{HDL}(\mathrm{mg} / \mathrm{dl})$} & $40.3 \pm 16.8$ & $39 \pm 9.6$ & $38.4 \pm 9.6$ & $0.8 \#$ \\
\hline \multicolumn{2}{|c|}{ Triglyceride (mg/dl) } & $190.8 \pm 75.7$ & $172.0 \pm 53.2$ & $213.7 \pm 36.4$ & $0.05 \#$ \\
\hline \multicolumn{2}{|c|}{ Serum creatinine $(\mathrm{mg} / \mathrm{dl})$} & $1.1 \pm 0.37$ & $1.2 \pm 0.4$ & $1.0 \pm 0.3$ & $0.02 \#$ \\
\hline \multirow{2}{*}{ Urinary albumin } & Yes & $24(38.7 \%)$ & 14 & 10 & \multirow{2}{*}{$0.06^{\star}$} \\
\hline & no & $38(61.3 \%)$ & 12 & 26 & \\
\hline \multirow{2}{*}{$\begin{array}{l}\text { Intimal thickness } \\
(\mathrm{mm})\end{array}$} & Right & $0.74 \pm 0.15$ & $0.79 \pm 0.14$ & $0.68 \pm 0.12$ & $0.002 \#$ \\
\hline & Left & $0.73 \pm 0.15$ & $0.78 \pm 0.14$ & $0.67 \pm 0.12$ & $0.001 \#$ \\
\hline & & $\begin{array}{l}\text { Table-I. Chara } \\
\text { not applicabl }\end{array}$ & $\begin{array}{l}\text { tics of the popu } \\
\text { hi-square, \#stuc }\end{array}$ & test & \\
\hline
\end{tabular}

Many studies have been conducted to assess the association of diabetic retinopathy (DR) with measures of sub-clinical cardiovascular disease. ${ }^{17,18,19}$

There was a significant association of CIMT with diabetic retinopathy in our study. This has been observed in other studies also. ${ }^{16}$ The retinopathy was associated with poor glycemic control, dyslipidemia, albuminuria and higher creatinine. This was also observed in other studies. Diabetic patients with DR were observed to have longer duration of diabetes, higher glucose and $\mathrm{HbA1C}$ levels, and higher systolic blood pressure compared to the diabetic patients without DR. ${ }^{17}$

Other methods of measuring atherosclerosis like ankle-brachial index (ABI) alongwith CIMT showed as association of DR with low $A B I$ and high CIMT in the Atherosclerosis Risk in Communities Study (ARIC). ${ }^{18}$ The Cardiovascular Health Study (CHS), on the other hand, did not reveal the association of DR and carotid atherosclerosis. ${ }^{19}$ The Multi- ethnic Study of Atherosclerosis (MESA) also did not reveal the association of DR with CIMT, although this study did show that DR was related with CAC (coronary artery calcium) scores and low $\mathrm{ABI}$ (ankle brachial index) even after adjusting for the traditional cardiovascular risk factors. ${ }^{17}$

Presence of DR can independently predict cardiovascular events in diabetes. ${ }^{20}$ In a European study presence of retinopathy predicted the extent of atherosclerosis and the occurrence of carotid plaques. ${ }^{21}$ Atherosclerosis starts early in life and runs a long sub-clinical course. It is detected usually after the occurrence of a cardiovascular event at a time when it is quite extensive. Carotid Doppler is a non-invasive test that can be used to improve the predictive capacity of the current methods by employing both measurement of CIMT and the presence of carotid plaques. ${ }^{22,15}$

Patients both with type 2 and type 1 diabetes mellitus have higher CIMT compared to subjects without diabetes. ${ }^{23}$ DR has been observed to be 
independently associated with presence of carotid plaques in type 1 diabetes mellitus. ${ }^{24}$ More type 2 diabetes patients with DR had carotid plaques and a greater number of plaques as compared to patients without DR. ${ }^{25}$ Stenotic carotid plaque was associated with a higher stage of DR. ${ }^{26}$

High glycated haemoglobin ( $\mathrm{HbA} 1 \mathrm{c})$, longduration of diabetes, male gender, microalbuminuria and insulin therapy were found to be risk factors for the development of DR. ${ }^{27}$ The other associated risk factors in another study were anemia, dyslipidemia, systemic hypertension, pregnancy, nephropathy and CVD. ${ }^{28}$ Hyperglycemia has been designated as the most consistent risk factor for DR in type 1 diabetes mellitus. ${ }^{29}$

Another point of concern is the management of DR in patients with clinical or sub-clinical cardiovascular disease. Treatment of DR is through laser ablation or use of anti-vascular endothelial growth factor (anti-VEGF) therapy for treating advanced stages of DR. The anti-vascular endothelial growth factor (anti-VEGF) can hypothetically increase the risk of cardiovascular disease by inhibiting angiogenesis in the diabetic patient with myocardial ischemia. ${ }^{30,31,32}$ This would be a clinically important factor as patients with diabetes mellitus are twice as likely to die from cardiovascular causes associated with atherosclerosis as compared to the normal population. ${ }^{12}$

The association of a high CIMT with DR warrants a complete cardiac evaluation of the diabetic patient with DR in order to rule out sub-clinical cardiovascular disease. These patients are not only at risk of losing vision due to DR but are also at a higher risk of developing catastrophic cardiovascular disease.

This study was limited by the small sample size. Larger studies should be conducted to find the relationship between the grade of retinopathy and the thickness of carotid intima media. More studies should also be considered to assess the effect of treatment modality

\section{CONCLUSION}

Retinopathy is strongly associated with CIMT. Poor glycemic control, nephropathy, dyslipidemia and duration of diabetes also show association with retinopathy. Patients with retinopathy must be screened for sub-clinical cardiovascular disease.

\section{Copyright $@ 04$ Jan, 2019.}

\section{REFERENCES}

1. Shera, A.S.; Jawad, F.; Maqsood, A. Prevalence of diabetes in Pakistan. Diabetes Res. Clin. Pract. 2007, 76, 219-222.

2. Abdollahi A, Moghimi S, Tabasi A, Rajabi MT, Sabet B. Neuropathy and retinopathy in diabetes: Is there any association? Int J Ophthalmol 2009; 2(1):57-60.

3. Zhang X, Saaddine JB, Chou CF, Cotch MF, Cheng YJ, Geiss LS, et al. Prevalence of diabetic retinopathy in the United States, 2005-2008. JAMA. 2010; 304:64956. [PMCID: PMC2945293] [PubMed: 20699456].

4. Lind M, Svensson AM, Kosiborod M, et al. Glycemic control and excess mortality in type 1 diabetes. $\mathrm{N}$ Engl J Med. 2014; 371:1972-82.

5. Brownlee M. The pathobiology of diabetic complications: A unifying mechanism. Diabetes. 2005; 54:1615-25.

6. Arcidiacono MV, Traveset A, Rubinat E, et al. Microangiopathy of large artery wall: a neglected complication of diabetes mellitus. Atherosclero- sis. 2013; 228:142-7.

7. Cheung N, Mitchell P, Wong TY. Diabetic retinopathy. Lancet. 2010; 376:124-36.

8. Gerstein HC, Ambrosius WT, Danis R, et al. Diabetic retinopathy, its progression, and incident cardiovascular events in the ACCORD trial. Diabetes Care. 2013; 36:1266-71.

9. Almeida FK, Esteves JF, Gross JL, Biavatti K, Rodrigues TC. Severe forms of retinopathy predict the presence of subclinical atherosclerosis in type 1 diabetes subjects. Arq Bras Cardiol. 2011; 97(4):346-9.

10. Araszkiewicz A, Rogowicz-Frontczak $A$, Zozulinska-Ziolkiewicz D, Pilacinski S, Wykretowicz A, Wierusz-Wysocka B. Presence of retinopathy in type 1 diabetic patients is associated with subclinical macroangiopathy. Scand J Clin Lab Investig. 2011; 71(7):563-8. 
11. Weber LA, Cheezum MK, Reese JM, et al. Cardiovascular imaging for the primary prevention of atherosclerotic cardiovascular disease events. Curr Cardiovasc Imaging Rep. 2015; 8:36.

12. Bashir F, Nageen A, Kidwai SS, Ara J. Carotid intimamedia thickness and cardiometabolic risk factors in Pakistani type 2 diabetics. Saudi J Health Sci 2017; 6:145-50.

13. O'Leary DH, Polak JF, Kronmal RA, et al. Thickening of the carotid wall. A marker for atherosclerosis in the elderly? Cardiovascular health study collaborative research group. Stroke. 1996; 27:224-31.

14. Chambless LE, Heiss G, Folsom AR, et al. Association of coronary heart disease incidence with carotid arterial wall thickness and major risk factors: The atherosclerosis risk in communities (ARIC) study, 1987-1993. Am J Epidemiol. 1997; 146: 483-94.

15. Nambi V, Chambless L, Folsom AR, et al. Carotid intima-media thickness and presence or absence of plaque improves prediction of coronary heart disease risk: The ARIC (atherosclerosis risk in communities) study. J Am Coll Cardiol. 2010; 55: 1600-7.

16. Miyamoto $\mathrm{M}$, Kotani $\mathrm{K}$, Okada $\mathrm{K}$, Fujii $\mathrm{Y}$, Konno $\mathrm{K}$, Ishibashi $\mathrm{S}$, et al. The correlation of common carotid arterial diameter with atherosclerosis and diabetic retinopathy in patients with type 2 diabetes mellitus. Acta Diabetol. 2012; 49:63-8. [PubMed: 21528431].

17. Kawasaki $\mathrm{R}$, Cheung $\mathrm{N}$, Amirul Islam FM, Klein R, Klein BEK, Cotch MF, Sharrett AR, O'Leary D, Wong TY. Is diabetic retinopathy related to subclinical cardiovascular disease? Ophthalmology. 2011; 118(5): 860-865.

18. Klein R, Sharrett AR, Klein BE, et al. The association of atherosclerosis, vascular risk factors, and retinopathy in adults with diabetes: The atherosclerosis risk in communities study. Ophthalmology. 2002; 109(7):1225-34. [PubMed: 12093643].

19. Klein R, Marino EK, Kuller LH, et al. The relation of atherosclerotic cardiovascular disease to retinopathy in people with diabetes in the Cardiovascular Health Study. Br J Ophthalmol. 2002; 86(1):84-90. [PubMed: 11801510].

20. Kramer CK, Rodrigues TC, Canani LH, Gross JL, Azevedo MJ. Diabetic retinopathy predicts all-cause mortality and cardiovascular events in both type 1 and 2 diabetes: Meta-analysis of observational studies. Diabetes Care. 2011; 34:1238-44.
21. Carbonell M, Castelblanco E, Valldeperas X, Betriu A, Traveset Maeso A, Granado-Casas M, et al. Diabetic retinopathy is associated with the presence and burden of subclinical carotid atherosclerosis in type 1 diabetes. Cardiovasc Diabetol. 2018; 17:66.

22. Gepner AD, Young R, Delaney JA, et al. Comparison of coronary artery calcium presence, carotid plaque presence, and carotid intima-media thickness for cardiovascular disease prediction in the multi-ethnic study of atherosclerosis. Circ Cardiovasc Imaging. 2015; 8:e002262.

23. Sun YP, Cai YY, Li HM, Deng SM, Leng RX, Pan HF. Increased carotid intima- media thickness (CIMT) levels in patients with type 1 diabetes mellitus (T1DM): A meta-analysis. J Diabetes Complicat. 2015; 29:724-30.

24. Distiller LA, Joffe BI, Melville V, Welman T, Distiller GB. Carotid artery intima-media complex thickening in patients with relatively long-surviving type 1 diabetes mellitus. J Diabetes Complicat. 2006; 20:280-4.

25. Alonso $\mathrm{N}$, Traveset $\mathrm{A}$, Rubinat $\mathrm{E}$, et al. Type 2 diabetes-associated carotid plaque burden is increased in patients with retinopathy compared to those without retinopathy. Cardiovasc Diabetol. 2015; $14: 33$.

26. de Kreutzenberg SV, Coracina A, Volpi A, et al. Microangiopathy is independently associated with presence, severity and composition of carotid atherosclerosis in type 2 diabetes. Nutr Metab Cardiovasc Dis. 2011; 21:286-93.

27. Pradeepa R, Anitha B, Mohan V, Ganesan A, Rema M. Risk factors for diabetic retinopathy in a South Indian type 2 diabetic population - The Chennai Urban Rural Epidemiology Study (CURES) eye study 4. Diabet Med 2008; 25:536-42.

28. Davis MD, Fisher MR, Gangnon RE, Barton F, Aiello LM, Chew EY, et al. Risk factors for high-risk proliferative diabetic retinopathy and severe visual loss: Early treatment diabetic retinopathy study report \#18. Invest Ophthalmol Vis Sci 1998; 39:233-52.

29. Sabanayagam C, Yip W, Ting DS, Tan G, Wong TY. Ten emerging trends in the epidemiology of diabetic retinopathy. Ophthalmic Epidemiol 2016; 23:209-22.

30. Wirostko B, Wong TY, Simó R. Vascular endothelial growth factor and diabetic complications. Progress in retinal and eye research. 2008 Nov 1;27(6):608-21.

31. Ueta T, YanagiY, TamakiY, Yamaguchi T. Cerebrovascular accidents in ranibizumab. Ophthalmology. 2009 Feb $1 ; 116(2): 362-$ 
32. Nicholson BP, Schachat AP. A review of clinical trials of anti-VEGF agents for diabetic retinopathy. Graefe's Archive for Clinical and Experimental Ophthalmology. $2010 \mathrm{Jul} 1 ; 248(7): 915-30$.

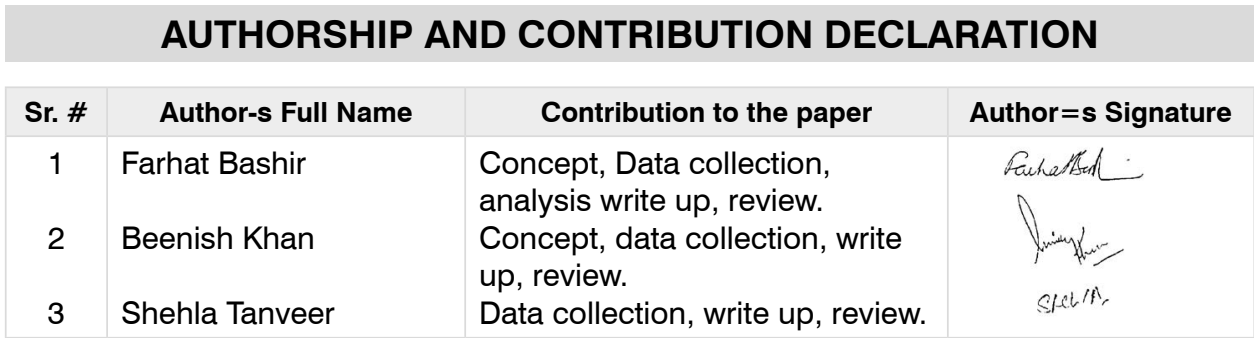

